\title{
Tank C6A Solids
}

by

H. P. Holcomb

E. I. du Pont de Nemours and Company

Savannah River Site

Aiken, South Carolina 29808

Dentrution of

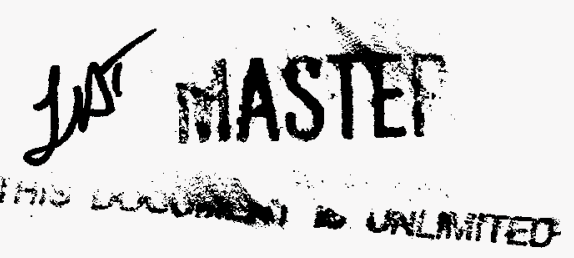

DOE Contract No.

This paper was prepared in connection with work done under the above contract number with the $U$. S.

Department of Energy. By acceptance of this paper, the publisher and/or recipient acknowledges the U. S.

Government's right to retain a nonexclusive, royalty-free license in and to any copyright covering this paper, along with the right to reproduce and to authorize others to reproduce all or part of the copyrighted paper. 


\section{DISCLAIMER}

This report was prepared as an account of work sponsored by an agency of the United States Government. Neither the United States Government nor any agency thereof, nor any of their employees, makes any warranty, express or implied, or assumes any legal liability or responsibility for the accuracy, completeness, or usefulness of any information, apparatus, product, or process disclosed, or represents that its use would not infringe privately owned rights. Reference herein to any specific commercial product, process, or service by trade name, trademark, manufacturer, or otherwise does not necessarily constitute or imply its endorsement, recommendation, or favoring by the United States Government or any agency thereof. The views and opinions of authors expressed herein do not necessarily state or reflect those of the United States Government or any agency thereof.

This report has been reproduced directly from the best available copy.

Available to DOE and DOE contractors from the Office of Scientific and Technical Information, P. O. Box 62, Oak Ridge, TN 37831; prices available from (423) 576-8401.

Available to the public from the National Technical Information Service, U. S. Department of Commerce, 5285 Port Royal Road, Springfield, VA 22161. 


\section{DISCLAIMER}

Portions of this document may be illegible in electronic image products. Images are produced from the best available original document. 
Solids

Tank C6A

\section{INTER-OFFICE MEMORANDUM}

Plutonium

Recovery

Savannah River Plant

DPSPU-88-272-24
March 9, 1988 $\mathrm{CC}^{\#} 244000$

TO: J. L. ADAMS, 221-F B-LINE

FROM: H. P. HOLCOMB, 772-F thot

\section{INFORMATION ONLY}

TANK C6A SOLIDS

INTRODUCTION AND SUMMARY

The Separations Technology Laboratory was requested to characterize solids, removed as a slurry, from cleanout of Tank C6A last month. For some time, solids had been appearing in samples taken from this tank.

The sample was a rather viscous, tan-colored semiliquid. It consisted of two solid fractions: 1) large, easily centrifuged particles (16 mL total) and 2) fine particles that were difficult to centrifuge into a solid mass ( $23 \mathrm{~mL}$ solids plus interstitial liquid). The fractions were kept separate during all testing. Both were dried to a temperature of $300^{\circ} \mathrm{C}$, in increasing steps, in order to remove water. The solids were finally collected in separate wide-mouthed plastic bottles and reduced in size and homogenized by vigorously shaking the capped containers.

The large fraction on drying yielded $13.840 \mathrm{~g}$; the smal1, 3.714 g. Analysis by the F B-Line gamma pulse height analysis (PHA) waste monitor indicated a $\mathrm{Pu} 239$ content of $4.92 \mathrm{~g}(36.6 \mathrm{wt} \%$ ) in the former and $1.73 \mathrm{~g}(55.5 \mathrm{wt} \%)$ in the latter after sampling had reduced the solids' weight by $0.4-0.6 \mathrm{~g}$. The other primary constituent of the larger particles was aluminum. For the fines, aluminum and calcium were major cation contributors, other than plutonium. Isotopic analysis by gamma PHA indicated both materials to be $12 \% \mathrm{Pu}^{240}$.

Particle size analysis of the smallest fines showed a distribution between 1 and $32 \mu \mathrm{m}$ with the mean being $6.55 \mu \mathrm{m}$ and the median, $6.18 \mu \mathrm{m}$. Some $22 \%$ of the particles were $2 \mu \mathrm{m}$ or less.

$95 \%$ of the plutonium, theoretically present in a sample of the large, dried particles, was recovered in solution by heating the solids in $8 \mathrm{M} \mathrm{HNO}_{3}$ at $90-95^{\circ} \mathrm{C}$ for 1.5 hours with efficient mixing. 
DPSPU-88-272-24

J. L. ADAMS

Page 2

March 9, 1988

For the smaller particles, $96 \%$ of the theoretical Pu present was recovered under the same conditions. Small quantities $(<0.1 \mathrm{~mL})$ of residues persisted in both.

Small samples of each of the dried solids were equilibrated with hot, deionized water. Plutonium solubility of the larger particles was $0.6 \mathrm{wt} \%$, sample weight basis; for the smaller particles, $0.3 \mathrm{wt} \%$. Anion analysis by ion chromatography of a dilution of the larger particles' supernate showed $\mathrm{F}^{-}, \mathrm{NO}_{3}^{-}$, and $\mathrm{SO}_{4}^{-2}$ in a $2: 1: 3$ molar ratio. Nitrate molarity $\left(0.018\right.$ mols $\left.\mathrm{NO}_{3}-/ 5 \mathrm{~mL}\right)$ was 2.6 times greater than the soluble plutonium. A repetitive experiment for the smaller particles yielded a similar molar ratio for $\mathrm{F}^{-}, \mathrm{NO}_{3}{ }^{-}$, and $\mathrm{SO}_{4}^{-2}$. Phosphate, at a molar level 10 times less than nitrate $\left(0.007 \mathrm{mmols} \mathrm{NO}_{3}-/ 5 \mathrm{~mL}\right)$, was also detected. Soluble nitrate molarity was 2.3 times that of soluble plutonium. Sulfate's origin in Tank C6A is unknown. I would suspect it to be an impurity in the $60 \%$ aluminum nitrate process solution.

The analytical evidence from this study shows the solids, although principally plutonium and aluminum, to be a complex mixture, stoichiometrically. The solids have likely been forming over the past few years due to conditions leading to insolubility, primarily of aluminum nitrate, in Tank C6A. This mode of formation is probably responsible for the larger particles. Since aluminum nitrate crystals can be highly hydrated, small quantities of plutonium could have been carried along from the 150-200 $\mathrm{g} \mathrm{Pu} / \mathrm{L}$ mother 1 iquor. The smaller particles could have formed in the same manner, but since they contain more plutonium than the larger ones, they could have originated in upstream processing from $\mathrm{C} 6 \AA$ and have been fine enough to either bypass filtration or be passed along during line breaks to change filters or for other maintenance.

Routinely scheduled inspection and/or cleanout is recommended to prevent further buildup of solids in such process vessels.

\section{EXPERIMENTAL AND DISCUSSION}

\section{Sample Furnished and Pretreatment}

The sample sent to the Sep Tech Lab and placed in our glove box was contained in a wide-mouth plastic bottle. The sample was a thick, viscous slurry, tan in color. This color was similar to that of solids seen in previous C6A samples.

Using water, the slurry was divided between two Kimax ${ }^{\circledR} 30-\mathrm{mL}$ centrifuge cones. First, the fines were transferred to one tube since they were easier to suspend. Finally, the remainder of 
DPSPU $-88-272-24$

J. L. ADAMS

Page 3

March 9, 1988

the solids were transferred to another, similar tube. Since the water used to transfer the solids comprised the majority of the liquid, it was considered a wash and discarded.

Initial centrifugation produced $16 \mathrm{~mL}$ of larger particulates with a clear, almost colorless supernate, which was carefully decanted. These particles ranged from a few millimeters down to approximately one millimeter in rough diameter. Their color was primarily from dark shades of gray to off-white, although some tannish material was present.

Initial centrifugation of the finer material gave $23 \mathrm{~mL}$ of combined fines plus interstitial liquid with a supernate that contained the difficult-to-centrifuge particles. This supernate, containing the finest solids, was reserved for particle size analysis. The solids were a uniform tan color and appeared homogeneous throughout.

Drying of Solids

Each batch of solids was transferred to its individual porcelain crucible using a minimum quantity of water so that the crucible was filled to no more than one-third of its capacity.

The crucibles and their contents were placed in the muffle furnace in the glove box. The furnace was initially turned on at its lowest setting and took approximately one hour to reach $125^{\circ} \mathrm{C}$, indicated. After another hour, the temperature had reached $150^{\circ} \mathrm{C}$. At this point the furnace was turned off and left overnight to cool to ambient temperature. The next day, the furnace was slowly heated, in steps, over an eight-hour period to a final temperature of $300^{\circ} \mathrm{C}$, at which it remained for approximately one hour. Again, the furnace was turned off and allowed to cool to ambient conditions overnight. There was no indication of splattering or of sample loss due to the heating process.

Both solid fractions were easily removed from their respective crucibles. They were placed in individual, tared wide-mouth plastic bottles, similar to the original sample container. Each was weighed on the balance in the glove box. The quantity of solids from the larger particles weighed $13.840 \mathrm{~g}$; the smaller, $3.714 \mathrm{~g}$.

Sampling for Emission Spectrographic Analysis

Each container was capped and then vigorously shaken to reduce the particle sizes to a powder-like material in each bottle. Also, by doing this, a more representative sample of each could be taken for emission spectrographic analysis. Following that sampling, the sample of larger particles weighed $13.444 \mathrm{~g}$; the smaller, $3.117 \mathrm{~g}$. 
DPSPU-88-272-24

J. L. ADAMS

Page 4

March 9, 1988

\section{NDA Determination of $\mathrm{Pu}$ in Solids}

Each capped sample bottle with its solids was packaged in a $\frac{1}{2}$-gal. ice cream carton. F B-Line operations arranged for pickup and transport of the solids to the gamma PHA waste monitor. By its analysis, there was $4.92 \mathrm{~g} \mathrm{Pu} 239$ in the bottle of "large" particles and $1.73 \mathrm{~g} \mathrm{Pu} 239$ in the "smaller" particles' fraction. Therefore, based on the weight of the solids following emission spec sampling, the larger garticles were $36.6 \mathrm{wt} \% \mathrm{Pu}^{239}$ and the smaller were 55.5 wt\% Pu239.

\section{Isotopic Composition of Solids}

While B-Line had the samples, I requested that Laboratories Department determine the $\mathrm{Pu}$ isotopic distribution in each via their gamma PHA instrumentation. The following table gives their results.

TABLE 1

\section{ISOTOPIC COMPOSITION OF SOLIDS}

\begin{tabular}{ccc} 
& \multicolumn{2}{c}{ Weight Percent } \\
\cline { 2 - 3 } Isotope & "Large" Particles & "Small" Particles \\
\cline { 2 - 3 } 238 & 0.09689 & 0.10235 \\
239 & 86.04032 & 85.87396 \\
240 & 12.15400 & 12.28329 \\
241 & 1.45242 & 1.46929 \\
242 & 0.25638 & 0.27110 \\
$241(\mu g / g ~ P u)$ & 2827 & 3391
\end{tabular}

Therefore, both particle fractions consist of $12 \% \mathrm{Pu} 240$ material, as would be expected.

Emission Spectrographic Analysis of Solids

The following table gives the major and minor constituents of the samples, other than plutonium, that were determined by emission spec:

TABLE 2

COMPOSITION OF SOLIDS

"Larger" Particles "Smaller" Particles

Ma jor

Minor
A1

$\mathrm{Ca}, \mathrm{Cr}, \mathrm{Cu}, \mathrm{Fe}, \mathrm{Mg}$, $\mathrm{Ni}, \mathrm{Pb}, \mathrm{Si}, \mathrm{Sn}$
$\mathrm{Al}, \mathrm{Ca}$

$\mathrm{Cr}, \mathrm{Cu}, \mathrm{Fe}, \mathrm{Mg}, \mathrm{Ni}$, $\mathrm{Pb}, \mathrm{Si}, \mathrm{Sn}$. 
DPSPU $-88-272-24$

J. L. ADAMS

Page 5

March 9, 1988

As a remark to this analysis, it was reported: "非 (the '1arger' particles) was higher in everything with the exception of $\mathrm{Ca}$, $\mathrm{Ni}$, and $\mathrm{Pb}$ ". Since $\# 1$ had less wt\% plutonium as measured by NDA, this information that it had more contaminants supports the lower $w t \% \mathrm{Pu}$ found in it and the higher wt\% $\mathrm{Pu}$ found in "⿰⿰三丨⿰丨三一⿻ 2 (the "smaller" particles).

Particle Size Analysis

The original sample of the fines slurry was given to Laboratories Department for particle size determination using their Coulter Counter ${ }^{\circledR}$, Model TA-II. Table 3 on the following page is a copy of the actual printout from that analysis.

The "size" column lists the particle sizes in $\mu \mathrm{m}$. The third column is the vol\% of the total solids that particular particle size occupies. Of interest here is that the mean particle size of the fines was $6.55 \mu \mathrm{m}$; the median, $6.18 \mu \mathrm{m}$. Also note that 21.7 vol\% of the particles were $2 \mu \mathrm{m}$ or less. Therefore, unless a filter were totally efficient for removing $1 \mu \mathrm{m}$ particles, then some of these C6A solids could pass through a $1 \mu \mathrm{m}$-rated filter.

Dissolution of C6A Solids

In order to test dissolution characteristics of the dried C6A solids, an initial test, using $0.440 \mathrm{~g}$ of the "larger" particles and $0.446 \mathrm{~g}$ of the "smaller", was attempted in separate $10 \mathrm{~mL}$ portions of $0.5 \mathrm{M}(3 \%) \mathrm{HNO}_{3}$ since $\mathrm{I}$ was told by $\mathrm{B}$-Line personnel that initial attempts at dissolution were being made with $2 \%(0.32 \mathrm{M})$ $\mathrm{HNO}_{3}$. Since there was very little color throw to the acid upon vigorous mixing at ambient temperature, dissolution was essentially nil in the weak acid.

To the same weighed sample in each tube with the weak acid was added $10 \mathrm{~mL}$ of $15.7 \mathrm{M} \mathrm{HNO}_{3}$. Therefore, the resulting acidity was 8M. Even in the cold upon mixing, there was a slight greenish color throw to the liquid. To speed up dissolution, the tubes were placed in a boiling water bath for 1.5 hours with vigorous mixing by hand of each tube and its contents every 5 minutes. At the end of this period, the liquid in each tube had a deep green color like that of the $\mathrm{Pu}\left(\mathrm{NO}_{3}\right) 6^{-2}$ complex. The samples were allowed to stand overnight to cool.

The following morning, the samples had the following parameters: 
DPSPU-88-272-24

J. L. ADAMS

Page 6

March 9, 1988

\section{TABLE 3}

\section{PARTICLE SIZE ANALYSIS OF FINES}

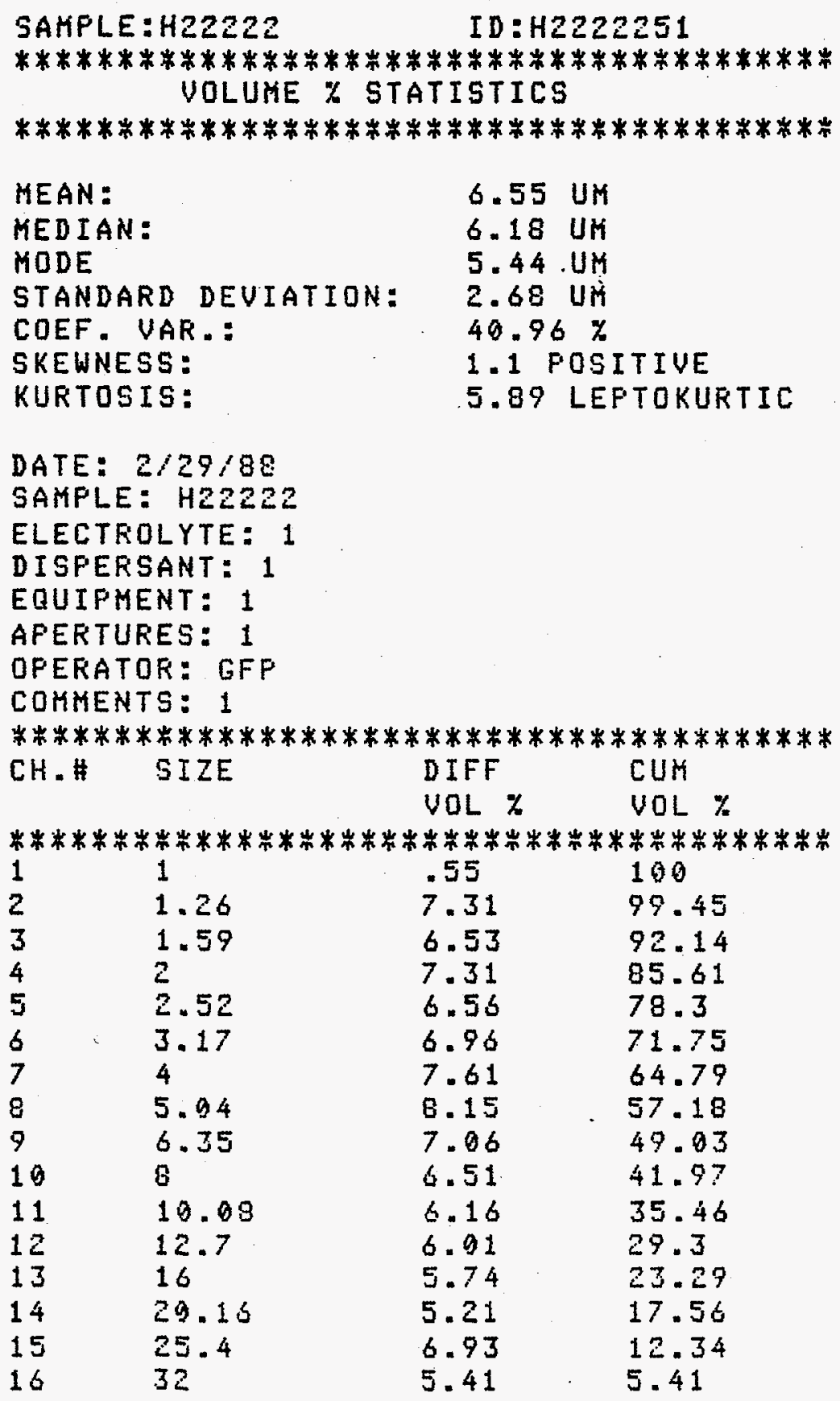


DPSPU-88-272-24

J. L. ADAMS

Page 7

March 9, 1988

"Larger" Particles

Total vol, $\mathrm{mL}$

Vo1. solids, mL

Total liquid volume, $\mathrm{mL}$
20.0

0.45

19.5
"Smaller" Particles

20.0

0.1

19.9

Material Balance and Accountability - Quantity of Pu Recovered On Dissolution

The contents of each of the centrifuge cones from the $8 \mathrm{M} \mathrm{HNO}$ dissolution were well mixed, then thoroughly centrifuged before taking the foregoing readings. Following these measurements, a 3-4 mL aliquot of each solution was submitted to Laboratories Department shift personnel for determination of its total plutonium content by the $\mathrm{Pu}^{+3}$ method using diode array spectrometry.

Their results showed the "Large" particle solution to be 9.12 $\mathrm{g}$ total Pu/L and the "Small" to be $13.99 \mathrm{~g}$ total Pu/L.

These data can be used to obtain a percent Pu recovery when combined with the data from the initial Pu value of each particle fraction and the isotopic analysis. The stepwise analytical progression follows :

"Larger" Particles "Smaller" Particles
(1) g dried solids taken
0.440
0.446 for dissolution

(2) total $\mathrm{g} \mathrm{Pu/L}$ in diss.

9.12

13.99 solution by diode array

(3) $\mathrm{g} \mathrm{Pu} / 19.5 \mathrm{~mL}$ of diss. sol.

0.178

0.278

(4) g Pu/g sample, \%,

$40: 4$

62.3

(3) $(\mathrm{X} 100) /(1)$

(5) original g solids counted

13.444

on gamma waste monitor

(6) $\mathrm{g} \mathrm{Pu} 239$ in sample by WM

4.92

1.73

(7) $w t \% \mathrm{Pu}^{239}$,

(6) $(\mathrm{X} 100) /(5)$

36.6

55.5

(8) isotopic wt\% $\mathrm{Pu} 239$

86.04

85.87

(9) total wt\% Pu in solids,

42.5

64.6

(7) $/(8)(X 100)$

(10) \% Pu recovery by hot $8 \mathrm{M}$ $\mathrm{HNO}_{3}$ leach,

95.0

96.4 (4) $(x 100) /(9)$ 
DPSPU $-88-272-24$

J. L. ADAMS

Page 8

March 9, 1988

Therefore, the heated, $8 \mathrm{M}$ nitric acid leaching of the solids, even though dried to $300^{\circ} \mathrm{C}$, recovered at least $95 \%$ of the total theoretical plutonium present as determined via gamma PHA. Efficient mixing was critical to effect such a high recovery.

Solubility of Solids in Water - Anion Analysis of Supernate

In an experiment to obtain information about the anionic content of the solids, approximately $0.2 \mathrm{~g}$ of each was equilibrated with separate $5-\mathrm{mL}$ portions of deionized water in a boiling water bath for one hour. Vigorous hand shaking was employed every 5 minutes for thorough mixing. At the conclusion of the equilibration period, the samples were thoroughly centrifuged. Water was used as the solvent to prevent interference in ion chromatography analysis by a large quantity of anion that would be found in an acid dissolvent (e. g., nitrate from nitric acid).

An aliquot of the supernate was removed for alpha analysis and for ion chromatography (IC). Due to the alpha content of the contact water, a dilution of the supernate in deionized water had to be made in order to sufficiently reduce alpha activity levels to acceptable limits for IC.

The following table gives the results of the alpha and IC analyses.

TABLE 4

HOT WATER EQUILIBRATION OF SOLIDS - SUPERNATE CONTENTS

Larger Solids Smaller Solids

g sample in $5 \mathrm{~mL} \mathrm{DI} \mathrm{H}_{2} \mathrm{O}$

0.290

0.220

mmols dissolved $/ 5 \mathrm{~mL}$ :

$\begin{array}{lll}\mathrm{Pu} \text { (wt\% of sample) } & 0.007(0.6 \%) & 0.003(0.3 \%) \\ \mathrm{F}^{-} & 0.036 & 0.012 \\ \mathrm{NO}_{3}^{-} & 0.018 & 0.007 \\ \mathrm{SO}_{4}^{-2} & 0.045 & 0.023 \\ \mathrm{PO}_{4}^{-3} & \text { Not Detected } & 0.0007\end{array}$

Molar ratio: $\mathrm{Pu}: \mathrm{F}^{-}: \mathrm{NO}_{3}{ }^{-}: \mathrm{SO}_{4}{ }^{-2} \quad 1: 5: 3: 6 \quad 1: 4: 2: 7$

To be noted from these data are the following:

1) The molar ratio of plutonium to the other ions in both samples is quite similar; i. e., plutonium:fluoride:nitrate:sulfate 
DPSPU $-88-272-24$

J. L. ADAMS

Page 9

March 9, 1988

= approximately $1: 5: 2: 7$. This indicates that the water soluble species from each are similar in composition. Also, since the $\mathrm{Pu} / \mathrm{F}$ ratio is close to $1 / 4$, might not the insoluble $\mathrm{Pu}$ species be $\mathrm{PuF}_{4}$ ? $\mathrm{PuF}_{4}$ can precipitate from fairly acidic solutions, especially if there is minimal concentration of fluoride complexant $\left(\mathrm{Al}^{+3}, \mathrm{BO}_{3}-3\right.$, etc.) present. 1

2) Although the larger particles are about $40 \mathrm{wt} \% \mathrm{Pu}$ and the smaller, about $60 \mathrm{wt} \%$, about one-half as much plutonium dissolved in the water from the smaller as did from the larger particles. However, since less than 1 wt of the plutonium from each particle sample was soluble in water, then the bulk of the plutonium in each is rather insoluble in hot water, but $>95 \%$ soluble in hot $8 \mathrm{M} \mathrm{HNO}_{3}$.

3) The question, "Where did the sulfate come from?", has to be asked. For both particulate samples, sulfate ion had the highest molarity in solution. Is it a reagent or feed impurity? Was sulfate (or something that gives rise to sulfate such as sulfamic acid or ferrous sulfamate) somehow improperly added to the process sometime previously? Or has sulfate solids gradually built up from the sulfate impurity in the $60 \%$ ANN process solution? At $25^{\circ} \mathrm{C}$, in $6 \mathrm{M}$ $\mathrm{HNO}_{3}$, at $176 \mathrm{~g} \mathrm{Pu} / \mathrm{L}, 1$ imiting sulfate concentration is $0.103 \mathrm{M}$ in order to prevent precipitation of $\mathrm{Pu}\left(\mathrm{SO}_{4}\right)_{2}$. With increasing acidity, limiting sulfate concentration decreases. 2 So, under the proper conditions, sulfate could precipitate $\mathrm{Pu}^{+4}$.

\section{DCAP Analysis of Water Supernate For Cations}

Aliquots taken from a nitric acid dilution of the water supernate, made for alpha analysis, were submitted to Laboratories for DCAP analysis of the following ions: $\mathrm{Al}, \mathrm{Ca}, \mathrm{Fe}$, and $\mathrm{Si}$. The following table gives the results of that analysis.

\section{TABLE 5}

\section{DCAP ANALYSIS OF WATER SUPERNATE}

Larger Particles

$\mu \mathrm{g} / 5 \mathrm{~mL} \mathrm{mmol} / 5 \mathrm{~mL}$

A1

$\mathrm{Ca}$

Fe

Si
1190

375

2625

5000
0.044

0.009

0.047

0.178
Smaller Particles

$\mu \mathrm{g} / 5 \mathrm{~mL} \mathrm{mmol} / 5 \mathrm{~mL}$

$1495 \quad 0.055$

$625 \quad 0.016$

$4150 \quad 0.074$

$6100 \quad 0.218$ 
J. L. ADAMS

Page 10

March 9, 1988

These molar compositions, except for silicon, are very similar in quantity to those found for the anions in the same solution. However, all of the experiments were conducted in glass vessels, and the DCAP samples were stored in glass vials, all a source of silicon. However, silicon is a component of each batch of solids as determined by emission spec, so not all of the soluble silicon is impurity from the glass vials. Emission spectrographic analysis found the major constituents, other than plutonium, of the "larger" particles to be aluminum; for the "smaller", they were aluminum and calcium. The emission spec findings are substantiated by the above data. These data also show that one of the minor constituents, iron, was a relatively large contributor to the soluble cationic components of the hot water leach.

Combining these data with those from the anionic analyses, it is apparent that the composition of each solid sample was complex and not readily stoichiometrically assignable to the elements found present.

Examination of Dried Solids by SEM/XRF

Portions of each dried solid sample were forwarded to D. F. Steedly of ADD, SRL, for examination by Scanning Electron Microscopy/X-Ray Fluoresence (SEM/XRF) to gather further information about their composition. ADD does not yet have a contained X-Ray Diffractometer, so a powder pattern of the solids, and possible identification of the crystal structure, is not possible onsite.

Initially, the solids showed the presence of plutonium and aluminum in one sample. However, immediately following this cursory examination, the SEM/XRF unit went down for maintenance and upgrading. Following this, problems have occurred with their instrument that will necessitate a visit by the factory representative next week. In order to facilitate issue of this report, a separate followup involving just the SEM/XRF findings will be published later.

\section{CONCLUSIONS AND RECOMMENDAT:IONS}

1) The solids have probably been slowly building up in Tank C6A over the past $\mathrm{few}$ years. They are there as the result of three factors, one being the insolubility of aluminum nitrate and other compounds under certain conditions in Tank C6A, another is that they formed or were present upstream of $\mathrm{C} 6 \mathrm{~A}$ and were transported and deposited there, and the final factor involves solid formers or solids themselves in cold feed solutions. The solids do not appear to be undissolved oxides since greater than $95 \%$ of the plutonium in them was soluble in hot $8 \mathrm{M} \mathrm{HNO} 3$. 
J. L. ADAMS

Page 11

March 9, 1988

2) The solids contain a substantial quantity of plutonium as noted from the analyses. This could result from sorption or from occlusion of the 150-200 $\mathrm{g} \mathrm{Pu} / \mathrm{L}$ mother liquor during crystallization of the solids, or from coprecipitation of the plutonium itself with the solids.

3) The solids contain sulfate from an unknown source. Essential Materials Specifications (EMS) for process $60 \%$ aluminum nitrate (ANN) call for sulfate, as $\mathrm{SO}_{4}$, to be no more than $0.05 \mathrm{wt} \%$, or $660 \mathrm{mg} \mathrm{SO} 4^{-2}$ per 1 iter of $60 \%$ ANN. According to $772-\mathrm{F}$ personnel, this analysis is still being conducted on vendor's samples. Another source of sulfate is from the hydrolysis of sulfamate ion, which is present in sulfamic acid or in ferrous sulfamate. Could either of these have been introduced into the process at some earlier time? I suspect the ANN impurity theory is much more plausible than the sulfamate one.

4) EMS for ANN solution also calls for "water insolubles" to be no greater than $0.01 \mathrm{wt} \%$, or $132 \mathrm{mg} / \mathrm{L} 60 \%$ ANN. This is not part of the acceptance criteria, although it is a specification. There are no analyses for "water insolubles". Could these "water insolubles" be contributing to the solids buildup in C6A? It would be interesting to calculate how much aluminum nitrate goes through the system during a given time period, and then calculate, based on 0.01 wt\% "water insolubles" in that aluminum nitrate, how much solids from this source would be available for formation of such residues .

5) Perhaps the best preventive measure for reducing solids buildup in such process tanks is regularly scheduled inspections and/or effective flushing operations for these vessels. For comparison, what does NSR plan to do with regard to such measures to prevent buildup of solids in their process tankage?

\section{ACKNOWLEGMENTS}

Several other groups contributed to the gathering of data that are included in this report. They should be recognized for their cooperative efforts. They include my own technical analyst, $N$. W. McGahee, for the quality manner in which he routinely conducts the many various laboratory operations, G. M. Blessing of Laboratories for getting the isotopic data from gamma PHA, B-Line personnel for obtaining the $\mathrm{Pu}$ content of the solids via the gamma PHA Waste Monitor, P. B. Berry of Labs for conducting the particle size analysis, J. T. Coleman of Labs for the emission spec and DCAP analyses, W. R. Frazier of Labs for the IC analyses, and the Laboratories' shift personnel for their usual fine job in doing the diode array analyses for $\mathrm{Pu}$ on the $8 \mathrm{M} \mathrm{HNO}_{3}$ dissolvents. 
